\title{
Study on the Restoration Aesthetic and Cultural Connotation of "Kintsukuroi" in Contemporary Lacquer Art
}

\author{
Wubin $\mathrm{Xu}$ \\ School of Art and Design \\ Wuhan University of Science and Technology \\ Wuhan, China
}

\author{
Yue Ma \\ School of Art and Design \\ Wuhan University of Science and Technology \\ Wuhan, China
}

\author{
Chenxi Xiao \\ School of Foreign Languages \\ Wuhan University of Science and Technology \\ Wuhan, China
}

\begin{abstract}
Literally, the Kintsukuroi refers to use the golden to repair the porcelain. It is originated from the piece of golden paint of the "Xiushi craft" in China. The craftsman would bond the broken pieces of porcelain with lacquer of natural resin. And then, they would use the gold foil to make the decoration. This article introduces the humanistic foundation of origin, development and formation of Kintsukuroi art. To repair broken porcelain with curium nails has a long history. It belongs to the restoration techniques. Kintsukuroi also inherited the restoration techniques. Essentially, it belongs to the field of lacquer art. In this paper, the author will also make the comparison between these two techniques in the crafts and the humanistic connotation. The appearance and glory of Kintsukuroi art originated from the general public's love for the precious porcelain in realities and the spiritual worship for the incomplete debris. The restoration aesthetics and cultural connotation contained in it are equally worth pondering. In this paper, it explores the embodiment of humanistic feelings in Kintsukuroi and its thinking and cognition.
\end{abstract}

Keywords-Kintsukuroi art; to repaire broken porcelain with curium nails; restoration aesthetics; cultural connotation

\section{INTRODUCTION}

In recent years, under the background of Japanese culture, the Kintsukuroi craftsmanship originated from China. It was born in and out of Japan. And thus, the concept of Wabi-sabi theory and incomplete aesthetics of the Kintsukuroi craftsmanship has become increasingly popular. In the art circle, ordinary people also begin to recognize this unique aesthetics. And it would give the utensils the second life of the repair technology. With the improvement of Kintsukuroi and market value, it is expected to set off a new wave of inheritance and rejuvenation of the traditional process. However, people in China and even those personnel in the domestic industry only know about Kintsukuroi. However, they only know about the technique and the process of creation. And they don't deeply consider the formation and development of the process. People would feel the repair aesthetics, cultural connotation and human feelings. We should study and analyze the humanistic foundation of the origination and development of Kintsukuroi craft. Comparing with the craft and connotation of repairing broken porcelain with curiu m nails in the country, it finally reflects the humanistic feelings in this craft. And it would help the public to understand creative concept of Kintsukuroi, analys is of works and unique ingenuity of creators. And then, people wouldn't just have the appreciation. They would understand universal values and aesthetic ideas of the craft and works.

\section{THE BACKGROUND OF THE DEVELOPMENT OF KINT SUKUROI IN LACQUER ART}

\section{A. The Origin and Introduction of Kintsukuroi}

"Kintsukuroi" is a kind of workmanship. The craftsman would fill the gap and take bonding or overall repair to deal with the ceramic artificially damaged pieces. They would take natural resin as the binder. And then, the craftsman would use the gold foil and gold powder to decorate the seams. This skill would restore the damaged debris. It would return the porcelain to its owner in good condition. The complete renovation would give new beauty and vitality to the artifacts. Essentially, it belongs to a category of lacquer. The craftsman would use resin liquid of lacquer tree to paint on the cracks. And then, it would be solid. It has the characteristics of corrosion resistant, acid and alkali resistant, solvent resistance, moisture and antimic robial bacteria. It has rich uses in practice. It has magnificent color. It will be wiped on the surface of the appliance. And it would protect the objects. Also, it would decorate and beautify the porcelain. Kintsukuroi is traditional restoration skill from 
Japan. It could repair the broken porcelain. Essentially, it belongs to a category of lacquer art. It is similar to "the skills of repairing broken porcelain with curium nails" in China. This technique can be used to repair porcelain, violet sand earthenware, bamboo ware, carpentry, ivory carving, jade ware and other appliances. They could repair a wide range of applications.

And the lacquer has life. As a kind of "breathing" material, in different seasons and temperature, they would have different performance. And it would require extreme temperature and humidity. The lacquer art is complex. And human experience, skills and the attitudes can't be ignored. The craftsman should behave step by step. It is a skill to restrain himself from showing off the cunning and cleverness. The lacquer material is produced from the lacquer tree. It is perennial deciduous tree. And it would produce the liquid. At the beginning, it is white. Then, it turns into red. Finally, it will infiltrate into black. It is mysterious. It is natural. And it can be used as medicine. The containers are made of lacquer. It has the properties of moisture resistance, high temperature resistance, corrosion resistance, and acid proofing and alkali resistance. China is rich in lacquer. The lacquer art appeared early in the Neolithic age. Untill the Shang dynasty, the lacquer ware was not only used in everyday life, but also served as a sacrificial offering. In Qin and Han dynasties, the carcass was lightweight, glossy and magnificent. The lacquer ware took the place of bronze ware. And it had been the valuable things. The lacquer ware was flourishing. During the Tang, Song and Yuan dynasties, lacquer crafts reached their peak. During this period, Japan began to introduce lacquer ware and its skills to China. The damaged surface of porcelain was bonded with natural lacquer. And then, the craftsman would use gold foil to decorate the cracks. The original fragmented utensils turned to glory, warm and longlasting golden things. This is Kintsukuroi.

\section{B. The Formation of Kintsukuroi}

The Kintsukuroi is from Japan. We can see it in "Leech and Tea pot". And this book was written by Ito Dong ya in Edo period. During the Muromachi period, the General Shogun Ashikaga Yoshimasa got a teacup produced by Longquan kiln in southern Song dynasty. And he loved it very much. However, due to the accidents, the tea bowl was broken into several pieces. And Ashikaga Yoshimasa felt very sorry. And he sent the envoy guiding the trade caravan to China. He wanted to get the same tea bowl with the government's help. It was a long time from the Song dynasty. The messengers did not get this tea bowl. Then, the messenger listened to the Chinese suggestion. The Chinese craftsman would repair the broken teacup with curium nails. (Now, this tea bowl is collected in the Tokyo Museum. And it is the national treasure of Japan). However, to repair broken porcelain with curium nails would be the secondary "damage". It belongs to the eye-catching process. And with Japan's unique aesthetic background, they can't accept and understand this skill. Although the craftsman repaired tea bowl well, Ashikaga Yoshimasa weren't very satisfied with it. And he lost the interest in it. Due to this unsuccessful restoration, the Japanese artisans began to create restoration techniques combining practical restoration and Japan's unique aesthetics. Therefore, Kintsukuroi drives from Chinese lacquer and gold craft. And then, it is developed in the Japanese aes thetics.

\section{The Humanistic Foundation of the Development of Kintsukuroi Craft Work}

As mentioned above, Kintsukuroi craft originated in Japan. It seemingly is the restoration skill. In fact, it belongs to lacquer art. In "Treasure and creature - Lacquer and my pottery creation", the crafts of covering with gold was similar to Kintsukuroi in "Xiushilu" written in late Ming dynasty. However, at that time, it didn't us e lacquer to repair the broken porcelain. [1] The Japanese repair the porcelain with gold. We can see that the Japanese don't care practical functions. However, it reflects the spirit of respecting the nature and cherishing the body. They could accept the incomplete things. And they could frankly accept the imperfection. In Japan, Zen and Tea aesthetics have laid the tone of Japanese aestheticis $m$ with taking imperfection as the beauty and advocating incompleteness. Only by understanding the related Japanese aesthetics can we understand the profound meaning and connotation of Kintsukuroi craft. And we will not repair the porcelain just for Kintsukuroi. Kintsukuroi should do something.

The Kintsukuroi has been passed on since five centuries ago. It can be traced back to the end of the fifteenth century. It stems from the concept of the Japanese Wabi-sabi. The socalled Wabi-sabi is Japanese unique aesthetic concept. As described above, the Japanese would seek the beauty in incompleteness and imperfection. However, in another opinion, Kintsukuroi derive from Japanese Mottainai. That is to say, people love something very much. And they don't want to give it up.

All kinds of the concepts, they belong to Japan's special aesthetics. Pink gold is one kind of restoration material of Kintsukuroi. It also shows that Japanese craftsmen appreciate and admire the beauty of the incompleteness. Japanese craftsmen calmly accept the defects and imperfections. People would keep the pursuit of beauty in the impermanent world. The repair technology is developing with the times. Kintsukuroi is used for restoration of porcelain, jade ware, bamboo ware, wood ware and other objects. [2]

\section{COMPARISON OF HUMANITIES AND CRAFT BETWEEN KINT SUKUROI AND REPAIRING BROKEN PORCELAIN WITH CURIUM NAILS}

\section{A. Comparison of Craft between Contemporary \\ Kintsukuroi and Repairing Broken Porcelain with Curium Nails in Ancient Times}

We know that the craftsman would repair broken porcelain with curium nails. The craftsman would use curium nails to repair the cracks. And it looks like leech. And it is known as leech knot. It is often made of copper and iron. So metimes, the craftsman would use the gold. To repair broken porcelain with curium nails is the most ancient restoration technique in China. And it could be tracked to the 
early days of the Song dynasty. It has at least the history of 10 centuries. Zhang Zeduang also paints a craftsman with concentration on the restoration in "Riverside Scene at Qing ming Festival". The Italian missionary Matteo Ricci in the Ming dynasty also included the wonder of the porcelain restoration in his book "The Story of China". It showed tremendous touches and surprises on this art. As the saying goes, "If the craftsmen have no diamond, they can't take the porcelain restoration." And this sentence comes from ancient and fine craft. "Fig. 1"

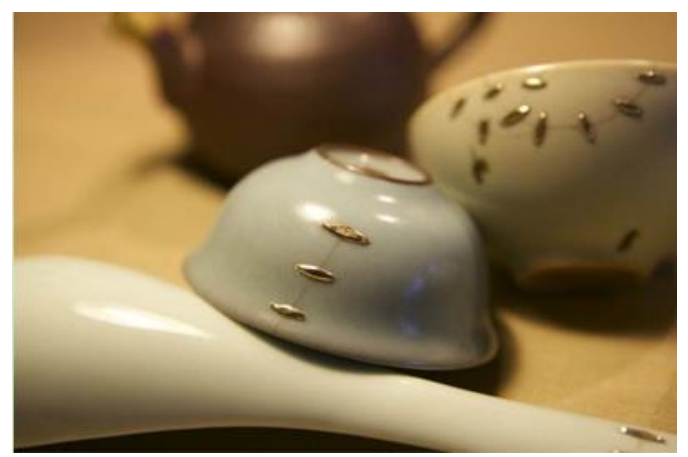

Fig. 1. The works of repairing broken porcelain with curium nails.

Kintsukuroi belongs to extremely popular traditional manual skills. And it is a Japanese word. Tracing the source, the so-called Kintsukuroi or golden restoration originated in the gold mud of Chinese "Xiushi". And the restoration materials are mainly the lacquer and gold foil. Strictly, it belongs to the field of lacquer. The craftsmen would use natural and chemical lacquer to fill the gap. And then, they would spread gold powder or gold foil on the surface. The cracks are filled with gold. And the incomplete would be prominent. However, it isn't significantly strange. Compared with the complete works, the restoration works would have special romantic charm. And the craftsmen use their experience to repair porcelain. ("Fig. 2")

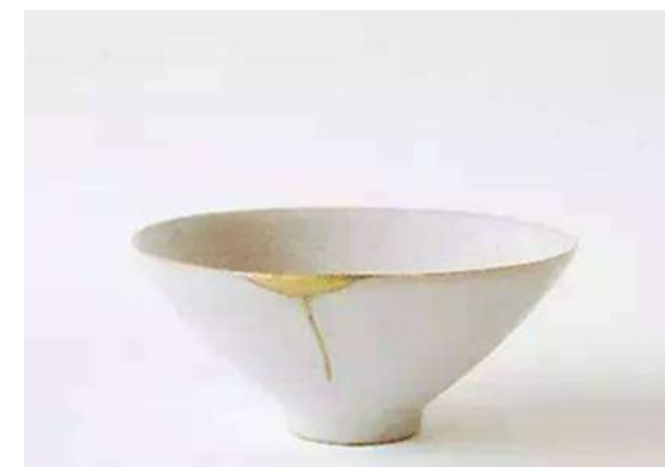

Fig. 2. Kintsukuroi works.

Kintsukuroi is traditional lacquer art. It was made by the Chinese nation. Therefore, some domestic scholars disagree with the opinion that Kintsukuroi drives from Japan. Furthermore, the scholars cited the classics. They had such opinions. In "Xiushilu", there would have such writings of "repairing the ancient utensils" [2]. Regardless of the origin or the creation, they think that Kintsukuroi can better maintain the integrity of the broken artifacts. However, repairing broken porcelain with curium nails wouldn't have such functions.

However, in terms of functions and difficulty of the art, Kintsukuroi and curium nails should have their advantages and disadvantages. Kintsukuroi is another creation of technology. It gives the second life to the restored artifacts. And it would have profound meaning and expression.

\section{THE COMPARISON OF HUMANIST IC CONNOT ATION BETWEEN CONTEMPORARY KINT SUKUROI AND REPAIRING BROKEN PORCELAIN WITH CURIUM NAILS IN ANCIENT TIMES}

For Chinese people, porcelain is not limited to the actual vessels. And it is emotional sustenance. Therefore, to repair the damaged objects would give it a new life. Also, it would repair broken feelings. The re-creation of art is also reflected in the process of restoration.

"Curium restoration would be destructive. Curium restoration would punch holes in the utensils. Therefore, the craftsmen would make the design plan before each restoration based on the characteristics of artifacts (shape, pattern, size, etc.). It is hoped that the restored objects will have practical functions. At the same time, it also has some ornamental and artistic features. [3]

Chen Xiaoling, an expert on lacquer art in Fujian province said: "The old curium porcelain does not seem to be as restrained and light as the modern works. Instead, the craftsmen would combine the technical characteristics of curium nails with the texture of the utensils. It seems to be random. However, it has mysterious principles. There are differences between the master who had punched ten thous and curium nails and the apprentice. "

However, under the special aesthetic background of advocating Wabi-Sabi and the beauty of incompleteness, it is not hard to understand that repairing broken porcelain with curium nails would bring second "harm" to the artifacts. And they can't accept and comprehend the crafts.

Kintsukuroi strives to make the damaged utensils show different charm. And the damaged utensils are given the practical value and ornamental ornamental value. This is different from repairing broken porcelain with curium nails. The craftsmen can't expect the damaged utensils. However, the damaged utensils can be repaired completely. And it could keep the value of porcelain. With the restoration crafts of Kintsukuroi and the cultural connotation, people would love and cherish the things. And it includes humanistic feelings and cultural connotation. As the saying goes, "to make up the bowls would fill up people's hearts". In fact, it is to repair people's heart of "cherishing the objects".

The purpose of Kintsukuroi is to treat imperfection with perfect attitudes and approaches. The gold is scarce. And the gold represents the philosophical thinking of artisans and philosophers. The craftsmen wouldn't conceal the defects. And they would use the most precious things to deal with the defects. They would painstakingly repair the defects. And the 
craftsmen would accept the impermanence in the world. And they would pursue the beauty forever.

\section{HUMANIST IC FEELINGS IN KINTSUKUROI WORKS}

\section{A. The Restoration Aesthetics of Kintsukuroi: "To Keep the} Beauty and Cherish Things"

"Kintsukuroi" is very complicated. And it has quite strict requirements for the craftsmen. It must keep the harmony of the creation. The restoration process of Kintsukuroi is main ly divided into five fields. The first is to clean the utensils. The craftsmen would clean various impurities on the damaged parts of artifacts. The craftsmen would use different methods to deal with different utensils. During the restoration process, it is an important step. As the second step of the whole process, to polish the porcelain is the basic work to bond the damaged porcelain. The adjustment and treatment of the objects should be carried out by grinding. The next step is to bond the cracks. The craftsmen would add a certain amount of flour to increase viscosity. With pressing the flour, the craftsmen would put it on the lacquer. And then, the craftsmen would fill the gap. After bonding the cracks, they would put the lacquer on the damaged area. The craftsmen would put flour on the lacquer. Then, the craftsmen should put it aside for a while. And they would repeat the process. The damaged area could be repaired. And then, they would polish the porcelain again.

The fifth step is to put the gold on the surface. During this process, the craftsmen would put gold foil and gold powder on the cracks. And they would repeatedly press the lacquer and sweep the gold. And then, the craftsmen would place the damaged porcelain in closed environment. And it would dry the damaged porcelain. The most exciting and important part of Kintsukuroi are to put the gold on the surface. It is a magical step. This would give artistic vitality to Kintsukuroi art. "Kintsukuroi would keep the beauty." During the process, any step is indispensable. And the craftsmen need to devote their hearts. In this process, the craftsmen should pay attention to some conditions. That is to dry the porcelain. Due to the thickness, humidity and material properties, the porcelain needs different time to be dried. The length of time will be reflected in the final effect. The craftsmen should be meticulous. Then, people would cherish the things.

\section{B. The Incompleteness of Wabi-Sabi}

As an important beacon symbolizing Japan's special aesthetics, "Wabi-Sabi" depicts the incomplete beauty. When the flawless porcelain was accidentally broken, "perfect thing" would be instantly became a pile of fragmentation. And it is "ugly". However, "the beauty can be lured from ugliness. Beauty is a dynamic event that takes place among people and things. There is an appropriate environment, thread or viewpoint, the beauty can germinate naturally. Therefore, beauty is the transition in consciousness. And it represents special poetic and elegant moment. [4] (Liou Na Keren) Cultural origins of Kintsukuroi are based on the pursuit of Japanese incomplete beauty. And it also derives from the process practice on the basis of this idea.
It is formed in Japan. Its unique culture of the tea ceremony also deeply affects artistry and related aesthetic guidance of Kintsukuroi. Since the 14th century, the Japanese tea ceremony has given priority to the cons picuous display of the tea ware. In the 16th century, Riky established the Japanese tea ceremony. Riky inherited and learned the spirit of the ancient tea ceremony. The purpose is "harmony, respect, clarity and silence". He would find the Wabi-Sabi in the "wamono". It abolished the pursuit of Tang things in the Muromachi era. Its purpose is to show the beauty of the vicissitudes of life under the old appearance of artifacts. And "Wabi-Sabi" advocated the natural cycle of life and death. They wanted to find the unique beauty in the imperfection. Based on this humanistic sentiment and spiritual connotation, the craftsmen developed Kintsukuroi. Under the influence of Japanese tea culture, Kintsukuroi gradually takes root and grows into professional career. And then, they create a new and original aesthetic concept rooted in Japan's unique culture.

\section{REFLECTION ON HUMANIST IC FEELINGS IN KINT SUKUROI CRAFT S AND WORKS}

Usually, Kintsukuroi would put little gold foil on the cracks. In the daily life, people often wipe and bump the porcelain. With long-term use, the gold foil will be worn. It would have no shiny gold. Therefore, the appearance of Kintsukuroi is elegant. Essentially, it is fragile. It needs owner's care. The flickering golden cracks on the artifacts would have the unique appearance and beauty. Instead of hiding cracks, Kintsukuroi emphasizes the sense of fragmentation. And then, it reveals the unique sense of history. After the restoration, the utensils transcend the original beauty. And it would have new life.

However, the rendering effect of Kintsukuroi art is also limited by the type of object, shape, the length, width, depth and size of the cracks, processing method, the thickness and length of lines, density, and weakness and so on. Different ways would lead to different results [5]. To carry out repairs and to create different aesthetic images on the original flavor of the objects is to consider the artistic attainments and skillfulness of the creators. Moreover, it is necessary to dig deeper into each other to understand the true meaning of the objects and maximize the subjective initiative. "It is to dance with the handcuffs". As a restoration technique, Kintsukuroi aims to reduce the "sense of incompleteness", pay attention to respecting the original works of artifacts and the original author's original intention. It doesn't advocate eye-catching repairs. Therefore, Kintsukuroi artists can't make too much decoration or performance. Due to the imperfections, uncertainties, uniqueness and theatricality of the artifacts, people would recognize and respect Kintsukuroi over time. The broken artifacts appear in the world with complete gestures. And Kintsukuroi gives a new life to the objects. It gives the owner the sense of satisfaction. With special beauty, it would strike the vision and make compensation for the soul. Kintsukuroi could repair the porcelain. And it would give second life to the objects. However, people would cherish the things. And these things would make people feel happy. 


\section{CONCLUSION}

In this study, the author investigated the origin and formation and humanist foundation of Kintsukuroi. The author has made the comparison of technological characteristics and humanistic connotation between Kintsukuroi and repairing broken porcelain with curiu m nails. Finally, the author analyzed and studied humanistic connotation and craftsman complex behind the process. However, as mentioned above, the research of Kintsukuroi in China is mainly on the crafts. It has not considered the profound influence of aesthetic philosophy and humanistic connotation. Based on this purpose, the paper eventually explores and finds Wabi-sabi and inventiveness contained in Kintsukuroi. For those collectors and viewers, this achievement would make them understand the arts and crafts. For the researchers and craftsmen, the research would be better.

Among them, it also explores the origin and ownership of Kintsukuroi craft in depth. Finally, it has made a conclusion that Kintsukuroi drives from China and grows up in Japan. Also, this paper gives a reasonable explanation for these historical and controversial is sues.

Kintsukuroi could repair the utensils. We should cherish the beautiful objects and friends. The study finally got the Kintsukuroi craftsmen complex and cultural connotation. It would be helpful to domestic research in related fields. And the domestic Kintsukuroi would pay attention to the romantic charm and appearance of the porcelain. The utensils would be beautiful. And people would cherish it. With the development of the crafts, it should pay attention to "vividness". It should adhere to the craftsmanship. And then, we could carry forward Kintsukuroi.

\section{REFERENCES}

[1] Zhai Zhenhui. Treasure and creature - Lacquer and my pottery creation [D]. Hangzhou: China Academy of Art, 2015.

[2] Yang Heng. Study on the design of "Xiushilu" [D]. Wuhan: School of Art and Design, Wuhan University of Technology. 2008.

[3] Rong Shukun, Niu Xiaoting, Wang Fenghu. Explanation on indoor furnishing art of Kang Baiwan Manor [J]. Shanxi Architecture, 2011 (22). p.5-6.

[4] Deng Bin. Kintsukuroi [J]. Art Observation, 2014 (10). p.94-97.

[5] Da Cha. Kintsukuroi and treasure [J]. China Collective Economy China Collective Economy China Collective, 2016(17). p.66-71. 